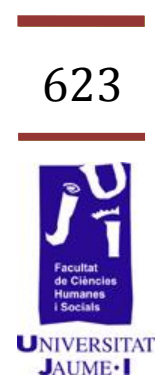

\title{
Cajun Vernacular English A Study Over A Reborn Dialect
}

Raúl Pérez Ramos al088623@alumail.uji.es 
I. Abstract

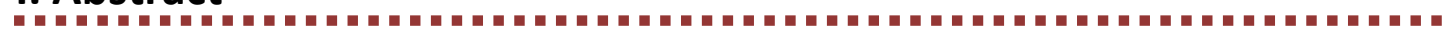

Cajun English is as dialectal variety of English spoken in the western areas of Louisiana which shows a strong influence of French language. It appeared a century ago when French speakers were forced to change their language to English. Yet, after the 1950s and because of racial segregation (Dubois and Horvath, 1999) and a political standardization of English language as the main language for American speakers this dialect was about to disappear. Despite this fact, the current situation of Cajun English is positive in the sense that it has been recovered by the youngest generations of speakers, who are proud of being Cajun.

The aim of this paper, thus, is to present the linguistic and social characteristics of Cajun Vernacular English. Concerning language, it presents peculiarities such as i) the elimination of final consonants, which involves grammatical consequences in the conjugation of verbs, ii) a reduction or absence of glides in the four long stressed vowels (Thomas, 2004), iii) a heavy nasalization of vowels, iv) the dropping of the aspirated consonant aitch and the replacement of interdental fricatives by stops, producing what is called "the paradigm 'dis, dat, dese, dose"" (Rubrecht, 1971) among others. Concerning social characteristics, this paper explores the reasons why this dialect is mainly used for tourism purposes as stated by Dubois and Hovarth 2003.

Paraules clau: Cajun Vernacular English, Louisiana, French, segregation, phonology

\section{Introduction}

The Oxford Dictionary defines the term dialect as "a regional variety of language distinguished by features of vocabulary, grammar and pronunciation from other regional varieties and constituting together with them a single language". There are a great number of dialects in the English language and the reasons which make them unique are very different. Cajun Vernacular English is a variety of English included within Southern American English dialects, sharing some of their variables but with a great influence from French language, which makes it distinctive from the rest of southern dialects. French language was brought to Cajun speaking areas by Acadians who moved to Nova Scotia -Canada- when the British took control of their lands around 1765 (Dubois and Harvorth, 2004: 407). Until the beginning of the twentieth century, French was the only language spoken at home by the descendants of French speakers, but English became progressively more used, and Cajun English appeared as a result. In three generations the dialect became widely used but ridiculed, then refused by their speakers, which made it almost disappear, and finally rescued by the youngest generations who feel Cajun as part of their own identity. This article deals with the characteristics of Cajun 
Vernacular English and the reasons which led to what has been called 'the Cajun Renaissance'.

\section{Historical Background}

The Cajun speech community covers the Gulf Coast from Texas to Mississippi but it is mainly concentrated in the small rural towns of southern Louisiana, being Lafayette its metropolitan center (see Appendix 1). Cajuns are the descendants of Acadians from Nova Scotia, Canada, who went to French Louisiana around 1765 when the British took control of their lands. In Louisiana they contacted with other French speaking populations as well as people who spoke other languages. The British purchased French Louisiana in 1803 and despite English became the official language of the state in 1812, Cajuns continued speaking French as their first language. They lived - as many continue to live today - in small towns and most of them were poor and had little education. Although some French descendants were considered as equal citizens, Cajuns were often ridiculed and made the butt of jokes.

In the 1930s English was the sole language of education in Louisiana, but it was not used in the Cajun communities. In addition, they did not learn English properly because most Cajun speakers attended school irregularly or left it early. English may have been the language in classroom, but French was the language of the streets. "It is this generation, people who are now sixty years or older who were forced to change their language and became the original speakers of the dialect we have labeled Cajun Vernacular English" (henceforth CajVE) (Dubois and Horvath, 1998a: 269), providing the linguistic source for succeeding generations. However, when the USA entered in World War II, Cajun English suffered an important decrease. People who joined the army were already bilingual or semi-bilingual due to the effort of Louisiana state government to enforce the speaking of English. After the WWII, the social changes that appeared had great influence in CajVE speakers. Children who had grown up in French-speaking homes began to have better learning of English than their parents, attended school more regularly and became wealthier. Many of this generation of speakers started to refuse French as a language in order to avoid the negative stereotypes associated with being a Cajun speaker and adopted American cultural ways. They began to use English at home and even the bilingual speakers abandoned French (Dubois and Horvath, 1999: 292).

Decades later, Cajun was only spoken by old people and middle generations rejected it completely. As a consequence, young generations suffered a sense of loss of Cajun culture and began to recover it. This process has been called the Cajun Renaissance. Nowadays, Cajun has an unprecedented status among their former original speaking territories but also among outsiders. Tourists are attracted by Cajun food, music and 
festivities, having also the support from the local government. However, bilingualism has almost disappeared and it is very unlikely to retrieve.

As not all Cajuns identify themselves with Cajun English, we can determine CajVE as an "ethnolect", particularly because that term seems to describe a speech community that changes its language of everyday communication to the politically dominant language, in this case English, and it is also a source of the language shift process that occurred. (Dubois and Horvarth, 2004: 408)

\section{Linguistic characteristics of CajVE}

There are two main phonological characteristics in CajVE. The first one is the elimination of final consonants. CajVE speakers do not pronounce most of the final consonants and they also drop some of the final consonants clusters [nd, st, Im]. This occurs not only in monomorphemic words but also in bimorphemic. CajVE speakers delete the final [t] in late or rent, [d] in hand, food or wide, $[\theta]$ in both, $[r]$ in together, [I] in school or simple, and both final [r] and [k] in New York, making the [rk] cluster disappear. There are also more important final absences, like final [v] in twelve, [s] in house or fence, $[\mathrm{n}]$ nine, $[\mathrm{m}] \mathrm{mom}$, [f] life and even the absence of [J] in fish. This phonological rule has an important consequence in grammar: final consonants which are also morphological markers are deleted at the word-ends. There will be further explanation on this matter in the following sections.

The second phonological characteristic is the reduction or absence of glides in the four long stressed vowels [i], [e], [o] and [u] in CajVE, similar to Southern English with the difference that stressed vowels and diphthongs are not prolonged (Thomas, 2004:303-304). The vowel [i] is pronounced in words such as me, street, and read with [i:], the vowel [e], as in way, make and take is pronounced with [e:]. The [o] in words such as know, both, and over, and the [u] in food, school, and two, are also realized as monophthongs [o:, u:] respectively. Mid vowels [o, e] are monophthongized more frequently than high vowels $[i, u]$. The diphthongs [ai], [av] and [ji] become monophthongs. Words with [ai] like fire, price or prize and with [av] like mouth or power are pronounced with [a:], and also words with [0i] like choice or oil lose their glide and become monophthongs pronounced with [0:].

Those two characteristics make CajVE qualitatively distinctive from Southern English as a separate dialect, and specially from American English. Other phonological features of CajVE include heavy nasalization of vowels ([b] nasalization in Alabama), the non-aspiration of $\left[p^{\prime}, t^{\prime}, k\right]$ in word-initial position preceding a stressed vowel (pat, pronounced like bat) or [ $r, \mathrm{l}, \mathrm{w}, \mathrm{j}]$ (plant, table and car), [h'] dropping (hair pronounced like air) and the replacement of interdental fricatives $[\theta, \delta]$ by stops $[t, d]$. As 
Rubrecht (1971: 152) points out: "the paradigm 'dis, dat, dese, dose' is well-known in Louisiana to describe how Cajuns talk". Although there is not clear how the substitutions of those possessive determiners came "one fact is fairly clear, all of them are stigmatized" (Dubois and Harvorth, 2004: 411).

As it was pointed above, the phonological elimination of final consonants has grammar consequences. The present tense marker in the third person singular (-S) disappears e.g. 'He gave me six'. 'She go with it'. And there is also an absence of the past tense morpheme (-ED) in weak verbs e.g. 'I stay two month', 'She wash my face'. Furthermore, CajVE has a high rate absence of the auxiliary of the verb to be in the third person in singular (IS), the second person singular and plurals (ARE) e.g. 'She pretty', 'He gonna meet her', 'What we doing?', 'You supposed to know that'. Figure 1 represents the percentage of these grammatical features that CajVE speakers do, distinguished by age and their mother tongue.

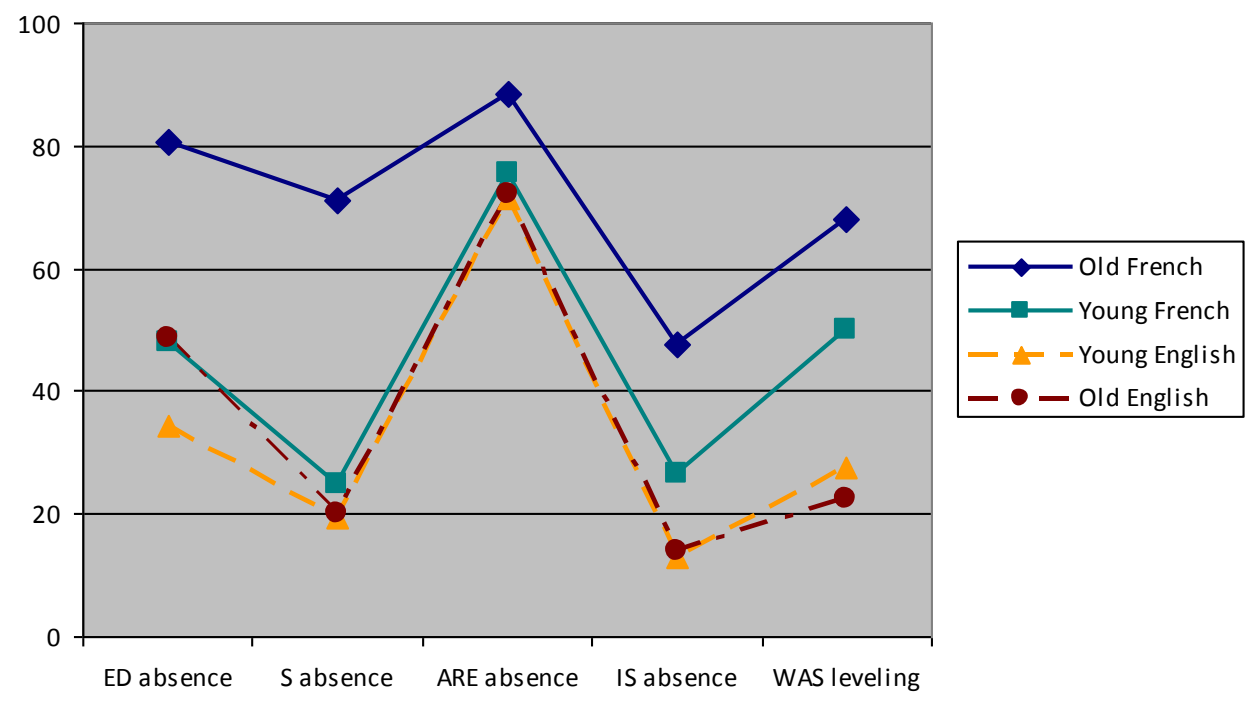

Figure 1. Percentage of occurrences of all variables according to four speaker groups (taken from Dubois and Horvath, 2003:40)

As we can see, the grammatical features above mentioned occur in many occasions, being the older generations who are original speakers of French the ones who use this kind of features more frequently. The "ARE absence" is the most usual in CajVE occurring more than $70 \%$ of occasions. 


\section{Social characteristics of CajVE}

Cajun English is nowadays recognized as an essential part of Cajun culture and preserved by local institutions. In 1968 Louisiana was declared officially bilingual, French was declared mandatory in high schools and the state established institutional relations with other francophone nations. Cajun speakers born after the 1970s are influenced by the Cajun Renaissance, they are proud to be Cajun and have also obtained important economic benefits due to the expanding tourism. However, the fact that Cajun is displayed mostly to outsiders reinforces the use of English as the official Cajun language, despite that French is the original language of Cajuns, changing the way in which Cajuns sound like. There is a clear separation between old generations of Cajuns and the youngest ones and, what is most surprising of all, between genders. As it was concluded by Dubois and Harvoth "young men return to the CajVE forms used by their grandparents' generation, while young women generally use the standard variants introduced by the middle-aged speakers. We have called this change led by young men in the direction of the former stigmatized and stereotyped CajVE variants 'recycling'" (Dubois and Harvoth 1999:292). Figures 2 and 3 show the clear difference in the pronunciation of dental stops between men and women.

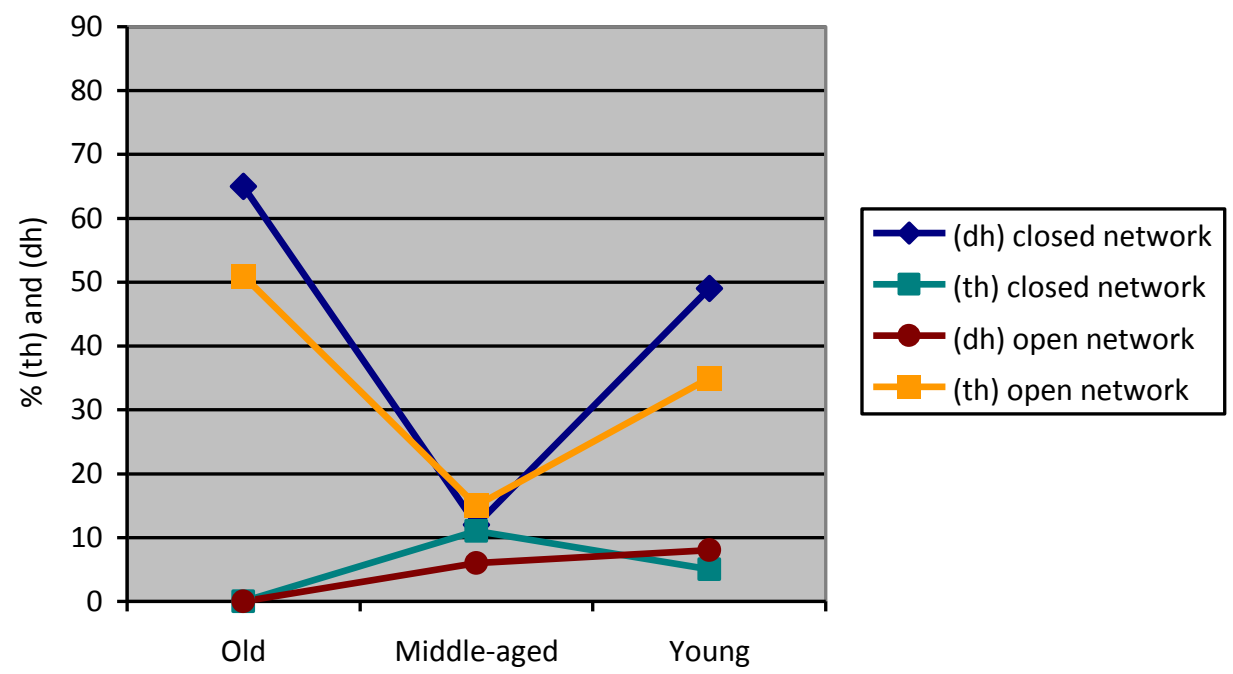

Figure 2. Percentage of Cajun variants among the three age groups. Dental stops among women (taken from Dubois and Horvarth, 1998b:254) 

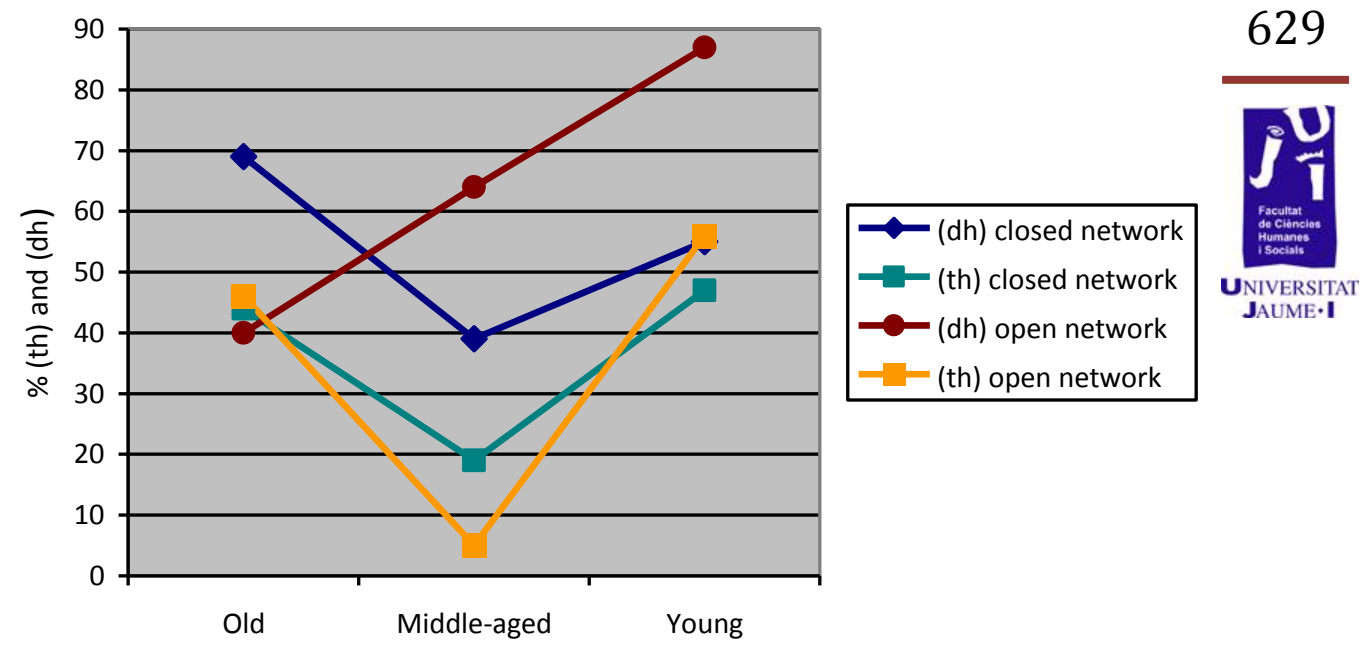

Figure 3. Percentage of Cajun variants among the three groups. Dental stops among men (taken from Dubois and Horvarth, 1998b:254)

The main reason for this is that the Cajun Renaissance affects traditional male activities such as boating, fishing, hunting or the traditional "courir du Mardi Gras", in which few women take part. Other important activities in Cajun culture like music and cooking are also mainly part of the male culture.

\section{Discussion}

Undoubtedly, the political institutions of Louisiana had a key factor in the Cajun Renaissance, not only because they comprehended it as a part of their cultural heritage but also an economical opportunity to attract tourists. If it wasn't for them, the segregation could have been the death of the dialect.

The relatively short history of sociolinguistics has shown that it is possible a combination of the commitment to the objective description of sociolinguistic data and also a concern for social issues. It is crucial for an endangered dialect that linguists have a proactive attitude towards the data they are studying.

Walt Wolfram and Natalie Schilling-Estes studied Ocacroke English, the dialect from Ocacroke Island, in North Carolina. This small island was relatively isolated for over two and a half centuries, and to this day is only accessible by ferry. This isolation produced a dialectal variety commonly known by the pronunciation of the diphtong [ay] as [jy]. In fact, their speakers are referred to as high tiders or "hoi toiders" because of their pronunciation of high tide as "hoi toid". In this case, the isolation that developed this dialect was geographical, not segregational, but it has similar traits with Cajun English. First of all, the influence of outside visitors has changed the dialect for the younger generations, who don't 
share the frequency of these phonological characteristics, and second of all, native older inhabitants are proud of their dialect and tend to exaggerate its most recognizable traits. Tourists tend to express curiosity for the dialect and it is known by them as one of the defining cultural elements of the island (Wolfram and Schilling-Estes, 1995).

Seeing that the dialect was about to disappear, the investigators concluded that they needed to inform about this endangered dialect to the widest audience possible. This was summarized in what was called the principle of linguistic gratuity (Wolfram 1993b):

Investigators who have obtained linguistic data from members of a speech community should actively pursue positive ways in which they can return linguistic favors to the community.

Thus, they had the obligation to document the dialect in a proper way, but also to raise the level of consciousness within and outside the community. This was transformed in the creation of several institutions for mantaining and preserving the dialect (the Ocacroke Preservation Society, the Ocacroke School and The Outer Banks Museum), tape recordings with extracts of real Ocacroke speech, a book about the dialect, t-shirts with typical phrases of Ocacroke and a documentary entitled 'The Ocacroke Brogue', among other things.

Wolfram and Schiling-Estes have taught us with this approach that linguists are obligated to have a proactive attitude towards an endangered dialect, which must be considered by the whole community as important as the rest of the characteristics of their cultural heritage.

Being now a dialect that is getting progressively attached to tourism activities in the western areas of Louisiana, the future of Cajun Vernacular English may not be bright. Therefore, a similar campaign like the one for Ocacroke English should be portrayed for CajVE in the long future in order to preserve this unique way of speech taking the work of Wolfram and Schiling-Estes as a model.

\section{Final remarks}

In less than a hundred years, Cajun English appeared as a dialect, it was about to disappear due to the segregation made towards their speakers and it has been recovered by the youngest generations, those who feel CajVE as part of their identity. Cajun English has unique phonological and grammatical characteristics that make it quite different from the rest of Southern American English dialects. Social characteristics are also determining and obligatory to define the dialect nowadays because when CajVE was recently recovered, the English language was considered the defining language of Cajuns instead of French due to 
tourism purposes, which changed the way Cajuns sound like and in what contexts is the vernacular used. As many men than women work in the tourism associated with Cajun culture, male speakers have developed CajVE in a stronger way. Cajun English has developed its own innovations not by migration movements or by being in contact with native speakers of English but by institutional decree.

Being now a dialect attached to tourism purposes, the future of CajVE is not clear in the long term. The work of Walt Wolfram and Natalie Schiling-Estes shows the measures that linguists should take for an endangered dialect based on their of principle of linguistic gratuity, teaching the speech community the importance of a dialect for their cultural heritage.

\section{Selected references (MLA citation)}

Dubois, Sylvie and Barbara Horvath (2004). "Cajun Vernacular English: phonology." In Bernd Kortmann and Edgar W. Schneider (Ed). A Handbook of Varieties of English: A Multimedia Reference Tool. New York: Mouton de Gruyter.

(2003). Verbal morphology in Cajun Vernacular English: A comparison with other varieties of Southern English. Journal of English Linguistics 31: 1-26.

(1999). When the music changes, you change too: Gender and language change in Cajun English. Language Variation and Change 11: 287-313.

(1998b). Let's tink about dat: Interdental fricatives in Cajun English. Language Variation and Change 10.3: 245-261.

(1998a). "From accent to marker in Cajun English: A Study of dialect formation in progress". English World-Wide 19.2: 161-188.

RUBRECHT, AUgUSt (1971). Regional phonological variants in Louisiana speech. PhD. dissertation, University of Florida.

THOMAS, ERIK R. (2004). "Rural Southern White Accents." In Bernd Kortmann and Edgar W. Schneider (Ed). A Handbook of Varieties of English: a multimedia reference tool. New York: Mouton de Gruyter.

Wolfram, Walt and Schiling-Estes, Natalie. (1995). Moribund Dialects and the Endangerment Canon: The Case of the Ocacroke Brogue. Language 71.4: 696-721

WolfRAM, WALt (1993). Ethical considerations in language awareness programs. Issues in Applied Linguistics 4. 227. 


\section{APPENDIX 1}

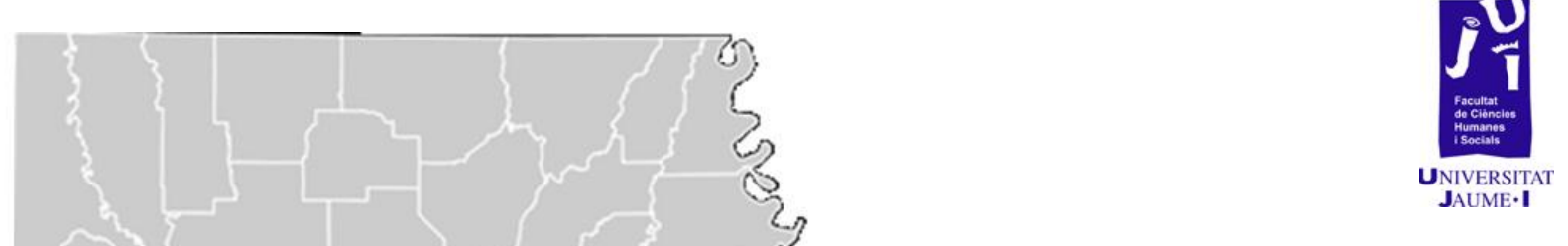

Figure 1. Map of the State of Louisiana. In red the 22 parishes in Southern Louisiana that belong to the Acadian Region with the "Cajun Heartland USA" subregion in a darker shade. 